\title{
Public debt, productive public spending and endogenous growth
}

\author{
Alfred Greiner
}




\title{
Public debt, productive public spending and endogenous growth
}

\begin{abstract}
Alfred Greiner*
Abstract

We analyze effects of public debt in a basic endogenous growth model with productive public spending. We demonstrate that a discretionary policy violates the inter-temporal government budget constraint along a balanced growth path. A balanced government budget gives a unique saddle point stable growth path. With a rule based policy, two saddle point stable balanced growth paths can occur, depending on the inter-temporal elasticity of substitution of consumption and on the primary surplus policy. Higher debt goes along with smaller long-run growth and we derive a condition such that a deficit financed increase in public spending raises the growth rate.
\end{abstract}

JEL: H60, O23

Keywords: Government debt, deficit rules, dynamics, endogenous growth

*Department of Business Administration and Economics, Bielefeld University, P.O. Box 100131, 33501 Bielefeld, Germany, agreiner@wiwi.uni-bielefeld.de 


\section{Introduction}

The financial crisis that started in the US in 2007 as a sub-prime crisis seemed to have been overcome in 2010 when the real economy had begun to grow again and catch up with its pre-crisis level. However, as a consequence of the bailouts by governments that had to back financial institutions in an unprecedented manner, public debt rose sharply generating a sovereign debt crisis in some European countries. Some euro area economies even had to be supported by others in order to avoid bankruptcy. Meanwhile, this crisis seems to have reached the real economy where economic growth rates tend to be low. It appears quite obvious that public debt does affect the development of market economies and in this paper we want to identify some effects of public debt with the help of a basic endogenous growth model.

When one intends to study the growth effects of public deficits and public debt, the question of how governments set the deficits is of utmost importance. In economics, the golden rule of public finance stating that governments should only run into debt in order to finance public investment is often mentioned as a reasonable guideline for policymakers. When benefits of public spending are generated over longer time horizons, it seems to be justified that the financing of such measures is also spread over time. Another rule is the tax smoothing rule introduced by Barro (1979). According to that rule governments should keep tax rates fixed and use public deficits to respond to variations in public spending and revenues. Thus, the excess burden of taxation can be kept to a minimum.

A rule that has gained much attention in the economics literature in the recent past is the so-called primary surplus rule stating that the primary surplus relative to GDP is a function that positively depends on the debt to GDP ratio. The economic rationale behind that rule is to make the debt ratio a mean-reverting process when the reaction of the primary surplus is sufficiently large, preventing the debt to GDP ratio from exploding. Concerning the empirical relevance one finds very strong evidence that governments do indeed act as if they followed that rule. For example, Bohn (1998) and Greiner et al. 
(2007) have shown that this rule holds for the USA and for selected euro area countries, respectively, using OLS estimations. Allowing for modern non-parametric estimation techniques, Fincke and Greiner (2011, 2011a) find that the reaction coefficient, determining the response of the primary surplus to public debt, is not a constant but time varying with the average of that coefficient being strictly positive for most countries.

An important aspect when studying long-run economic growth is the stylized fact that economic growth rates have been strictly positive and that there is no tendency for declining rates. Hence, a theoretical model that is to explain long-run growth should generate positive growth as an endogenous phenomenon. Usually, that is achieved by endogenous growth models and there are several economic mechanisms that may produce ongoing growth. One source of ongoing growth is to posit that government spending is productive and has positive effects on the marginal product of private capital, thus, generating permanent growth. That model goes back to Barro (1990) who took up an idea that had been first integrated into a formal economic model by Arrow and Kurz (1970). It was only recently, that the model by Barro (1990), that does not allow for public debt, has been extended by Kamiguchi and Tamai (2012) who integrated public deficit and public debt into that model and analyzed the question of under which conditions ongoing growth and sustainability of public debt are simultaneously achievable. ${ }^{1}$

There is a vast and growing body of empirical research that analyzes the correlation between public debt and economic growth. A frequently cited contribution is the one by Reinhart und Rogoff (2010) who, using histograms, find an inverted U-shaped relation between debt and growth, with the relationship becoming negative once the debt to GDP ratio exceeds about 90 percent. Although that paper seems to contain a spreadsheet coding error that led to a miscalculation of the growth rates of some economies, there are other studies that also detect an inverted U-shaped relation between debt and growth.

\footnotetext{
${ }^{1}$ Futagami et al. (2008) also analyze the Barro (1990) model with public debt, but assume that the ratio of public debt to GDP must not exceed a certain critical value, which strongly affects their analysis.
} 
Checherita und Rother (2010) perform regression analyses for 12 euro area countries over the period 1970-2011, where they distinguish between annual growth rates and growth rates over a time span of 5 years. For both cases, these authors also find an inverted U-shaped relation between debt and growth, with the threshold of public debt being at 70-80 percent of GDP. In addition, Checherita-Westphal et al. (2012) estimate regressions for various subsamples of OECD countries and find values for the threshold of the debt to GDP ratio that range between 43 and 63 percent of GDP. ${ }^{2}$ Egert (2012) extends the time period of the sample in Reinhart and Rogoff back to 1790 and detects a small negative correlation between debt and growth. Using an endogenous threshold model, he finds some evidence for a nonlinear relationship between debt and growth. Further, Egert (2012) points out that both the presence and the level of the thresholds are not robust to small changes in country coverage, data frequency and to changes in the assumptions on the minimum number of observations included in each regime.

On the other hand, there exist empirical studies that only find a negative correlation between the debt to GDP ratio and economic growth. Ferreira (2009), for example, performs Granger causality tests for 20 OECD countries over the time period from 19882001, where he studies annual growth rates. It turns out that higher debt to GDP ratios exert a negative effect on the growth rates of economies. This effect is statistically significant and it goes in both directions, that is higher public debt reduces economic growth and less growth implies higher government debt. Kumar and Woo (2010) analyze 19 countries over the time span from 1970-2007, where they estimate growth regressions with the growth rate over 5 years as the dependent variable. The result of their estimations is a definitely negative relationship between the debt to GDP ratio at the beginning of a period and the growth rate of that period. In addition, they investigate the relation between public deficits and economic growth and detect a negative correlation, too. Their

\footnotetext{
${ }^{2}$ However, within a theoretical endogenous growth model, one needs extreme assumptions to get an inverse U-shaped relation between debt and growth (cf. Greiner, 2013).
} 
study also reveals nonlinearities such that higher public deficits and higher debt to GDP ratios go along with disproportionately negative growth rates. Ballasone et al. (2011) analyze the relation between the ratio of public debt relative to GDP and the growth rate of real per capita income in Italy over the period 1861-2009. They detect a negative correlation between government debt and economic growth, where the negative effect seems to work mainly through reduced investment.

Panizza and Presbitero (2013), finally, present a survey of papers dealing with debt and growth. They find that the presence of thresholds and, more generally, of a nonmonotonic relationship between public debt and economic growth is neither robust to changes in data coverage nor to the empirical techniques resorted to. They maintain that empirical studies dealing with that subject should, in particular, put a strong emphasis on cross-country heterogeneity.

Thus, it seems that different countries may experience different growth effects from public debt suggesting that multiple equilibria may exist. Ghosh et al. (2013), for example, find that the reaction of the primary surplus to public debt is characterized by nonlinearities, with the reaction first being negative, then positive and again negative for very high public debt to GDP ratios. This gives rise to multiple long-run equilibria, the realization of which depends on the initial condition with respect to the public debt to GDP ratio.

In this contribution we intend to contribute to the question of how public debt can affect the allocation of resource in the long-run in an endogenous growth model with productive public spending. To do so, we take the model by Kamiguchi and Tamai (2012) as a starting point and generalize that model by allowing for a more general utility function. For that generalized model we are able to show that multiple balanced growth paths can arise, in contrast to Kamiguchi and Tamai (2012), without assuming a nonlinear relation between the primary surplus and public debt as in Ghosh et al. (2013). The emergence of multiple balanced growth paths depends on the inter-temporal elasticity 
of substitution of consumption and on the way how governments set the primary surplus. In addition, we also analyze a discretionary fiscal policy and a balanced government budget. We can demonstrate that a balanced government budget leads to higher long-run growth than permanent deficits and we show that a discretionary fiscal policy implies that the government violates its inter-temporal budget constraint on a balanced growth path. Finally, we derive conditions such that a deficit financed increase of public spending raises economic growth in the long-run.

An important role as concerns the emergence of multiple equilibria plays the intertemporal elasticity of substitution of consumption. Most of the empirical studies that estimate the inter-temporal elasticity of substitution find small values. However, there are substantial cross-country differences in this parameter and rich countries and economies with a high stock market participation substitute a larger fraction of consumption intertemporally in response to changes in expected asset returns. Havranek et al. (2013) perform a meta-analysis, where they study 167 contribution with more than 2700 estimates. They find a mean of 0.5 for the inter-temporal elasticity, but also point out that the estimates vary greatly between economies. In particular, there are also countries for which the point estimate clearly exceeds 1 so that high values for that parameter should not be considered as purely academic.

In the rest of the paper we proceed as follows. In the next section we present the structure of our model. In section 3 we analyze the endogenous growth model with productive public spending and public debt for different debt policies and section 4, finally, concludes the paper. 


\section{The growth model with productive public spending and public debt}

We begin our presentation with a description of the structure of our model that extends the basic endogenous growth model with productive public spending presented by Barro (1990) by integrating public deficits and public debt. Our model can also be seen as an extension of the Kamiguchi and Tamai (2012) model by assuming a more general utility function with constant absolute risk aversion instead of a logarithmic utility function.

\subsection{The private sector}

The private sector in our economy is characterized by a continuum of rational and identical households that have perfect foresight. Rationality in this framework implies that households maximize their utility over an infinite time horizon arising from per-capita consumption, $c(t)$, subject to the budget constraint. Population is constant and set equal to one. The maximization problem of the representative household can be written as, ${ }^{3}$

$$
\max _{c} \int_{0}^{\infty} e^{-\rho t}\left(c^{1-\sigma}-1\right) /(1-\sigma) d t
$$

subject to

$$
\dot{k}+\dot{b}=r b+(1-\tau) y-c
$$

The coefficient $\rho$ is the household's rate of time preference, $r$ is the interest rate and $1 / \sigma$ gives the inter-temporal elasticity of substitution of consumption between two points in time and the dot over a variable gives the derivative with respect to time. The variable $y$ gives GDP which is equal to output in the economy, $k$ denotes private capital where we neglect depreciation, $b$ is public debt and $\tau \in(0,1)$ is the constant tax rate on output.

Output $y$ is given by

$$
y=k^{\alpha} g^{1-\alpha}
$$

\footnotetext{
${ }^{3}$ We delete the time argument $t$ as long as no ambiguity arises.
} 
with $\alpha \in(0,1)$ the elasticity of output with respect to private capital and $1-\alpha$ the elasticity of output with respect to productive public spending $g$. In equilibrium the interest rate equals the net marginal product of capital and is given by

$$
r=(1-\tau) \alpha k^{\alpha-1} g^{1-\alpha}
$$

\subsection{The government}

Starting point of our considerations is the period budget constraint of the government that is described by the following differential equation,

$$
\dot{b}=r b-\tau y+g .
$$

In addition, the government sticks to the inter-temporal budget constraint given by

$\lim _{t \rightarrow \infty} e^{-\int_{0}^{t} r(\mu) d \mu} b(t)=0$, stating that the present-value of public debt converges to zero asymptotically.

In order to fulfill its inter-temporal budget constraint, the government sticks to the so-called primary surplus rule which states that the primary surplus relative to GDP, $p s / y$, is a function that positively depends on the debt to GDP ratio $b / y$ and on the term $\phi$ that reflects the discretionary scope of the government. This fiscal policy is called rule based, even if the government has some discretionary scope within that policy (through the choice of $\phi$ ), because it states that the primary surplus rises as public debt increases. However, below we also analyze a (purely) discretionary policy, where the primary surplus is independent of public debt.

Thus, the primary surplus is given by,

$$
\frac{p s}{y}=\beta\left(\frac{b}{y}\right)-\phi, \beta \in \mathbb{R}_{+}, \phi \in \mathbb{R},
$$

with $\beta$ the average reaction coefficient determining the reaction of the primary surplus to variations in debt, relative to GDP respectively, and $\phi$ showing how the level of the primary surplus varies as GDP rises. The coefficient $\phi$ may be positive or negative. For 
$\beta>0$ we get the rule based policy and the discretionary policy is obtained for $\beta=0$. With the primary surplus rule (6) the growth rate of public debt is obtained as,

$$
\frac{\dot{b}}{b}=r-\beta+\phi\left(\frac{y}{b}\right) \text {. }
$$

The government sticks to the primary surplus rule (6) such that the evolution of public debt is given by (7). This gives public spending as

$$
g=(\tau+\phi) y-\beta b
$$

Defining $c_{p}:=g / y$ as public spending relative to GDP yields $c_{p}=(\tau+\phi)-\beta(b / y)$ such that the production function can be rewritten as

$$
y=k c_{p}(x, \cdot)^{(1-\alpha) / \alpha},
$$

with $x:=b / y \geq 0$ the debt to GDP ratio, where we limit our analysis to the case where public debt is positive.

\section{Analysis of the model}

In this section we analyze our model where we first derive the differential equations that describe our economy.

Solving the optimization problem of the household, using $r=(1-\tau) \alpha k^{\alpha-1} g^{1-\alpha}=$ $(1-\tau) \alpha c_{p}^{(1-\alpha) / \alpha}$ as well as (7) leads to the following growth rates of consumption and of public debt,

$$
\begin{aligned}
& \dot{c}=c\left((1-\tau) \alpha c_{p}(x, \cdot)^{(1-\alpha) / \alpha}-\rho\right) / \sigma \\
& \dot{b}=b\left((1-\tau) \alpha c_{p}(x, \cdot)^{(1-\alpha) / \alpha}-\beta+\phi / x\right) .
\end{aligned}
$$

Finally, combining the budget constraint of the household, (2), with that of the government, (7), gives the economy-wide resource constraint as,

$$
\dot{k}=k\left(c_{p}(x, \cdot)^{(1-\alpha) / \alpha}\left(1-c_{p}(x, \cdot)\right)-z\right)
$$


with $z:=c / k$. Thus, the economy is completely described by equations (10)-(12) plus the usual transversality conditions.

To analyze our economy further, we define a balanced growth path.

Definition 1 A balanced growth path $(B G P)$ is a path such that consumption, capital and output grow at the same strictly positive constant growth rate, i.e. $\dot{c} / c=\dot{k} / k=\dot{y} / y=\gamma$, $\gamma>0, \gamma=$ constant, and either

(i) $\dot{b}=0$ (balanced budget) or

(ii) $\dot{b} / b=\dot{c} / c=\dot{k} / k=\dot{y} / y=\gamma$ (permanent deficit).

Definition 1 shows that we allow for two different scenarios in the long-run: First, a situation with a balanced government budget where the level of outstanding government debt is constant while all other economic variables grow at the same constant rate. Second, the scenario with permanent deficits where public debt grows at the same rate as all other variables.

Differentiating the variables $z$ and $x$ with respect to time leads to the following twodimensional differential equation system

$$
\begin{aligned}
\dot{z} & =z\left((1-\tau) \alpha c_{p}(x, \cdot)^{(1-\alpha) / \alpha} / \sigma+z-c_{p}(x, \cdot)^{(1-\alpha) / \alpha}\left(1-c_{p}(x, \cdot)\right)-\rho / \sigma\right), \\
\dot{x} & =x \psi(x, \cdot)\left(c_{p}(x, \cdot)^{(1-\alpha) / \alpha}\left((1-\tau) \alpha-1+c_{p}(x, \cdot)\right)-\beta+\phi / x+z\right)
\end{aligned}
$$

with $\psi(x, \cdot)$ defined as $\psi:=\alpha(\tau+\phi-\beta x) /(\alpha(\tau+\phi)-\beta x)$ where we used $\dot{y} / y=$ $\dot{k} / k+((1-\alpha) / \alpha) \dot{c}_{p} / c_{p}$ with $\dot{c}_{p}=-\beta \dot{x}$.

In the case of a balanced budget we have ${ }^{4} x^{\star}=0$ and $\dot{z}=0$ on a BGP so that $\dot{c} / c=\dot{k} / k=\dot{y} / y, \dot{c}_{p}=0$. With permanent deficits a BGP is obtained for $\dot{z}=\dot{x}=0$ which implies $\dot{c} / c=\dot{k} / k=\dot{y} / y=\dot{b} / b, \dot{c}_{p}=0$ and for the long-run debt to GDP ratio $x^{\star}>0$. First, we analyze the balanced government budget, case (i) in definition 1 .

\footnotetext{
${ }^{4}$ The star ${ }^{\star}$ denotes BGP values.
} 


\subsection{Balanced government budget}

Proposition 1 demonstrates that in the case of a balanced budget there is a unique saddle point stable BGP.

Proposition 1 Assume that the government runs a balanced budget. Then, there exists a unique BGP that is a saddle point.

Proof: See appendix.

Proposition 1 shows that in case of a balanced budget, the BGP is unique and saddle point stable. It can also be shown that the balanced budget scenarios always goes along with a higher balanced growth rate than the scenario with permanent deficits. The economic mechanism behind that outcome is that a zero debt to GDP ratio implies that the primary surplus relative to GDP also equals zero so that the government does not have to use public resources for unproductive interest payments and for the debt service. ${ }^{5}$ The result is stated in the following proposition 2 .

Proposition $2 A$ balanced government budget yields a higher balanced growth rate than a scenario with permanent deficits.

Proof: See appendix.

As concerns the dynamics, the case of permanent public deficits is more interesting because it may give rise to multiple BGPs as will be shown in the next subsection.

\subsection{Permanent public deficits}

When permanent deficits are allowed, one can distinguish between a purely discretionary policy where the primary surplus does not depend on the outstanding public debt, on the one hand, and a rule based policy where the primary surplus is a positive function of the

\footnotetext{
${ }^{5}$ We recall that we exclude the situation with a negative government debt.
} 
debt to GDP ratio, on the other hand. The first is modelled by setting $\beta=0$ such that the primary surplus only depends on the parameter $\phi$. However, such a policy implies that the government violates its inter-temporal budget constraint along a balanced growth path as proposition 3 shows.

Proposition 3 Assume that the government follows a discretionary policy. Then, the government violates its inter-temporal budget constraint along a balanced growth path.

Proof: See appendix.

The reason for the outcome in proposition 3 is that neither the economy-wide resource constraint (12) nor the growth rate of private consumption (10) depend on the debt to GDP ratio when the government pursues a discretionary fiscal policy. Then, the present value of public debt converges to a positive or negative finite value or to plus or minus infinity, depending on the initial debt to GDP ratio and depending on the primary surplus policy of the government. In any case, the inter-temporal budget constraint of the government is violated.

Therefore, we limit our analysis to the case $\beta>0$ in the following. This means that the government pursues a rule based policy in the sense that it raises the primary surplus as public debt grows, relative to GDP respectively. However, that does not mean that the government has no discretionary scope at all. Rather, it can determine public spending by the choice of the parameter $\phi$ to a certain degree. The following proposition first characterizes the long-run behavior of our economy for this case.

Proposition 4 a) For $1 / \sigma<1, \phi>0$ and for $1 / \sigma>1, \phi<0$ the existence of a BGP implies that it is unique.

b) For $1 / \sigma<1, \phi<0$ and for $1 / \sigma>1, \phi>0$ multiple BGPs can arise.

Proof: See appendix.

Proposition 4 shows that the inter-temporal elasticity of substitution of consumption, $1 / \sigma$, and the way how governments set the primary surplus as GDP rises, $\phi$, are decisive 
concerning the multiplicity of BGPs. We should like to point out that a positive (negative) value of $\phi$ implies that the primary surplus declines (rises) as the GDP increases, meaning that the government puts a small (large) weight on stabilizing public debt.

Part $a$ ) of proposition 4 demonstrates that the BGP is unique for a small inter-temporal elasticity of substitution of consumption, $1 / \sigma<1$, and when the government puts a small weight on stabilizing public debt, $\phi>0$. The latter means that the government prefers to raise productive public spending as GDP grows, rather than to reduce the accumulation of public debt. A low inter-temporal elasticity of substitution implies that the household is not very willing to forgo consumption today and shift it into the future as the interest rate rises. When the inter-temporal elasticity of substitution of consumption is high, $1 / \sigma>1$, uniqueness of the BGP is given when the government puts a high weight on stabilizing public debt, i.e. for $\phi<0$.

Part $b$ ) of that proposition illustrates under which conditions multiple BGPs can arise. With a small (large) inter-temporal elasticity of substitution, $1 / \sigma<1(1 / \sigma>1)$, multiple BGPs are obtained for a negative (positive) value of the parameter $\phi$, i.e. when the government puts a high weight on stabilizing debt (on growth enhancing public spending). From an economic point of view, multiple BGPs mean that there exists an underdevelopment trap in which the economy is caught. Thus, if the initial debt to GDP ratio exceeds a certain threshold, it is impossible for the economy to converge to the BGP going along with a relatively high growth rate. Instead, the economy converges to the low growth BGP in the long-run.

Proposition 4 states that multiple BGPs may occur depending on the inter-temporal elasticity of substitution of consumption and on how governments set the primary surplus as the GDP rises. In the following corollary to that proposition we give a condition for the emergence of exactly two BGPs.

Corollary 1 Assume that $(\tau+\phi)(\rho / \sigma)-\beta \tau<(>) 0$ holds for $1 / \sigma<1, \phi<0(1 / \sigma>1$, $\phi>0)$. Then, the existence of a BGP implies that there are two BGPs. 
Proof: See appendix.

Proposition 4 has given conditions under which the long-run BGP is unique and when multiple BGPs occur. Next, we analyze stability properties of our economy, where we assume that the condition of corollary 1 is fulfilled so that there exist two BGPs in the case of multiple BGPs. Proposition 5 gives the result.

Proposition 5 a) For $1 / \sigma<1, \phi>0$ the unique $B G P$ is saddle point stable if and only if $x^{\star}<\alpha \bar{x}$, with $\bar{x}:=(\tau+\phi) / \beta$. For $1 / \sigma>1, \phi<0$ the BGP is saddle point stable if and only if $x^{\star}>\alpha \bar{x}$.

b) For $1 / \sigma>1, \phi>0$ both BGPs are saddle point stable for $x_{1}^{\star}<\alpha \bar{x}<x_{2}^{\star}$, with $x_{1}^{\star}$, $x_{2}^{\star}$ the debt to GDP ratio on the first and second $B G P$, respectively. For $1 / \sigma<1, \phi<0$ at most one BGP is saddle point stable.

Proof: See appendix.

Note that the variable $\bar{x}$ is that value of the debt to GDP ratio for which public spending relative to GDP, $c_{p}$, becomes zero. Hence, the debt to GDP ratio cannot exceed the upper bar $\bar{x}$.

Proposition 5 a) demonstrates that the unique BGP is saddle point stable when the government puts a small weight on stabilizing public debt but instead prefers to raise public spending as GDP grows, provided the debt to GDP ratio on the BGP is relatively small, i.e. lower than $\alpha \bar{x}$. That makes sense from an economic point of view because with a small debt to GDP ratio, the goal of stabilizing public debt is less important than financing growth enhancing public spending. If, on the other hand, the debt to GDP ratio on the BGP is relatively large, i.e. $x^{\star}>\alpha \bar{x}$, the government must put a high weight on stabilizing public debt such that convergence to this BGP can be achieved. In that case, stabilizing public debt is more important than financing productive public spending.

In the case of two saddle point stable BGPs, proposition $5 b$ ), the economy converges to the high growth path when the initial debt to GDP ratio is smaller than the threshold $\alpha \bar{x}$. With an initial debt ratio larger than the threshold $\alpha \bar{x}$, the economy converges to 
the low growth path in the long-run. In the latter situation, the initial debt ratio is high, requiring a lot of public resources that cannot be used for productive public spending, so that only convergence to the BGP with the low growth rate is feasible. That situation occurs when the government puts a small weight on stabilizing debt, $\phi>0$, and when the inter-temporal elasticity of substitution of consumption is high, $1 / \sigma>1$. Figure 1 illustrates this case. The arrows on the linearized stable manifold of the two saddle points indicate the direction of movement of the two variables.

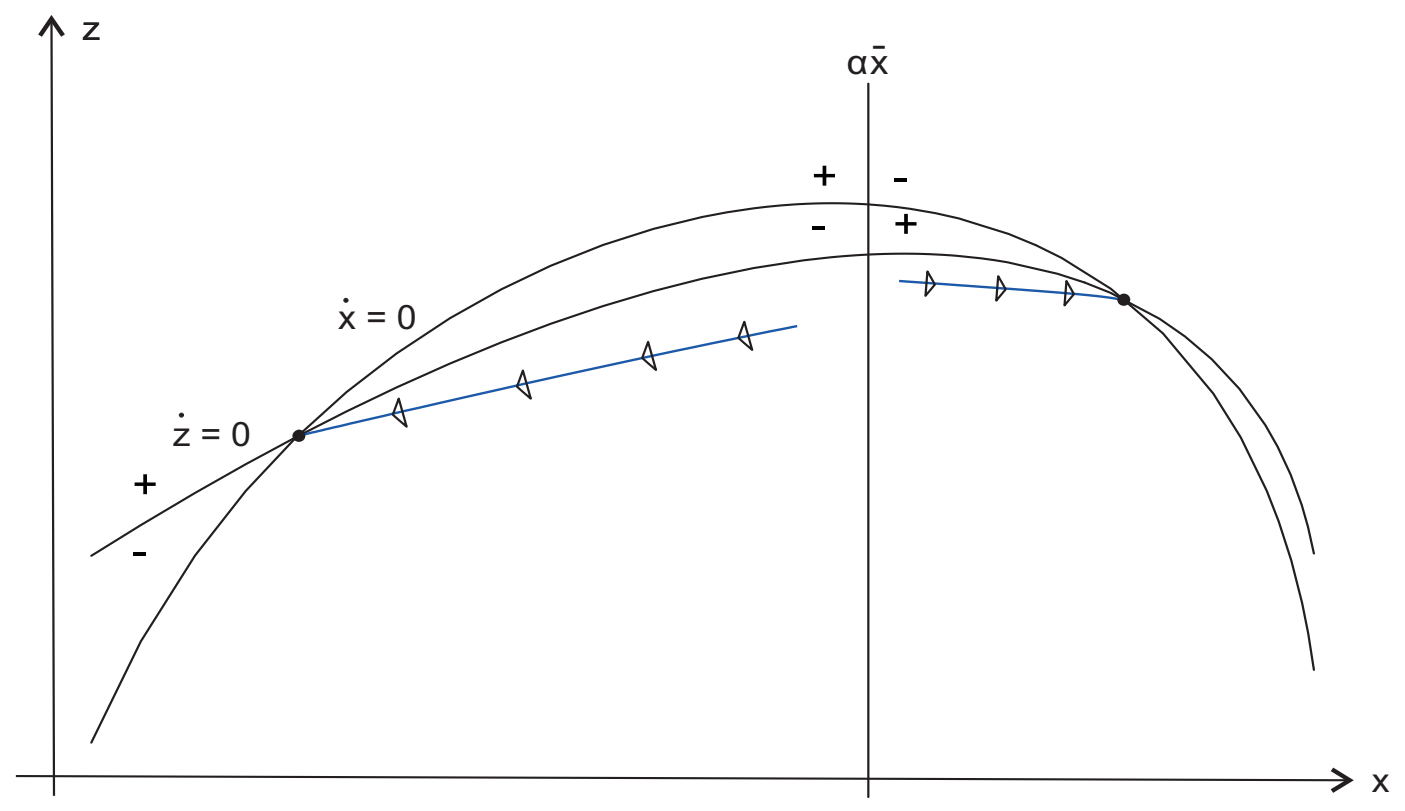

Figure 1: Two saddle point stable BGPs for $1 / \sigma>1, \phi>0$.

When the inter-temporal elasticity of substitution is small, $1 / \sigma<1$, multiple BGPs may also arise when the government puts a high weight on stabilizing public debt, i.e. for $\phi<0$. In that case, however, at most one of the two BGPs is saddle point stable because the household is not very willing to vary its initial consumption to private capital ratio (due to the small inter-temporal elasticity of substitution) for different values of the initial debt to GDP ratio which imply different interest rates. 
Before we next present some numerical examples to illustrate the emergence of multiple BGPs we derive a condition that must be fulfilled such that a deficit financed increase in public investment raises long-run growth.

Proposition 2 in section 3.1 has shown that a balanced government budget, where the debt to GDP ratio becomes zero on the balanced growth path, yields maximum growth. However, that does not mean that a deficit financed increase of productive public spending always reduces long-run growth. Instead, a situation is feasible where deficit financed public spending is productive in a way such that the initial increase in public debt is compensated so that the economy ends up with higher long-run growth. In order to get insight into that problem, we next perform comparative statics with respect to a deficit financed increase of productive public spending modelled by an increase in the fiscal parameter $\phi$. The result is given in proposition 6 .

Proposition 6 Assume that a saddle point stable BGP exists. Then, a deficit financed increase in productive public spending raises (reduces) the balanced growth rate if and only if the balanced growth rate falls short of (exceeds) $\bar{\gamma}=\left((1-\tau) \alpha c_{p}(\alpha \bar{x}, \cdot)^{(1-\alpha) / \alpha}-\rho\right) / \sigma$.

Proof: See appendix.

Proposition 6 shows that economies with a low balanced growth rate and a high debt to GDP ratio will experience positive growth effects of higher deficit financed productive public spending while the reverse holds for economies with high growth and a low debt to GDP ratio. In the case of two saddle point stable BGPs the balanced growth rate of the BGP with high growth declines while the growth rate of the BGP with low growth rises, which is equivalent to the outcome obtained in Futagami et al. (2008). Next, we present some examples to illustrate our analytical results for the case of multiple BGPs.

First we set $1 / \sigma=1.35$ and $\phi=0.065$ which gives rise to two BGPs. The other parameter values are $\alpha=0.7, \tau=0.35, \beta=0.15$ and $\rho=0.125$. Interpreting one time period to comprise 5 years implies that the annual rate of time preference is about 2.4 percent. The first BGP goes along with a growth rate of 18.9 percent that corresponds to 
an average annual growth rate of about 3.5 percent. The associated debt to GDP ratio is $x^{\star}=0.878$ which is smaller than $\alpha \bar{x}=1.94$. The eigenvalues of the Jacobian are given by $\lambda_{1}=0.171, \lambda_{2}=-0.093$. Note that we have $\rho-(1-\sigma) \gamma=0.076$ for this BGP such that the utility functional (1) remains bounded. The second BGP is associated with a growth rate of 0.8 percent that corresponds to an average annual growth rate of 0.16 percent meaning that this economy is stagnating. The associated debt ratio is $x^{\star}=2.4$. The eigenvalues of the Jacobian are $\lambda_{1}=0.194, \lambda_{2}=-0.076$ showing that this BGP is a saddle point, too.

To illustrate the outcome with $1 / \sigma<1, \phi<0$ we set $1 / \sigma=0.3, \phi=-0.015$ and $1 / \sigma=0.75, \phi=-0.0035$. Table 1 shows the results for this numerical example demonstrating that there exists only one saddle point stable BGP for this parameter constellation. ${ }^{6}$

\begin{tabular}{|c|ccccc|}
\hline $1 / \sigma, \phi$ & & eigenvalues & $x^{\star}$ & $\gamma$ & $\alpha \bar{x}$ \\
\hline $1 / \sigma=0.3$, & $1^{\text {st }} \mathrm{BGP}:$ & $\lambda_{1}=0.368, \lambda_{2}=0.076$ & 0.189 & 0.045 & 1.563 \\
$m=-0.015$ & $2^{\text {nd }} \mathrm{BGP}:$ & $\lambda_{1}=1.413, \lambda_{2}=-0.258$ & 1.518 & 0.015 & 1.563 \\
\hline \hline $1 / \sigma=0.75$, & $1^{\text {st }} \mathrm{BGP}:$ & $\lambda_{1}=0.293, \lambda_{2}=0.009$ & 0.295 & 0.111 & 1.617 \\
$m=-0.0035$ & $2^{\text {nd }} \mathrm{BGP}:$ & $\lambda_{1}=0.306, \lambda_{2}=-0.011$ & 0.762 & 0.089 & 1.617 \\
\hline
\end{tabular}

Table 1: BGPs for $1 / \sigma<1$ and $\phi<0$.

\section{Conclusion}

In this paper, we have extended the basic endogenous growth model with productive public spending as a flow by assuming that the government may run public deficits and public debt. We have seen that a discretionary fiscal policy, where the primary surplus does not react to public debt, implies that the inter-temporal budget constraint of the government

\footnotetext{
${ }^{6}$ The given growth rate refers to one time period interpreted as 5 years above.
} 
is violated along a balanced growth path. On the other hand, when the government runs a balanced budget there exists a unique saddle point stable balanced growth path that also yields maximum growth, compared to a path with permanent deficits.

In the case of a rule based fiscal policy, where the primary surplus rises as public debt increases, multiple balanced growth paths can occur, depending on the inter-temporal elasticity of substituion of consumption and on the way how governments set the primary surplus as GDP rises. Thus, an underdevelopment trap can arise for a certain parameter constellation, implying that an economy converges to a low growth path in the long-run if the initial debt to GDP ratio exceeds a certain critical threshold. Finally, we have seen that a deficit financed rise of productive public spending leads to higher long-run growth if and only if the balanced growth rate is smaller than a certain critical value.

\section{Appendix}

\section{Proof of proposition 1}

A balanced government budget implies $x^{\star}=0$. Using this it is easily seen that there exists a unique $z^{\star}>0$ by solving $\dot{z}=0$. The Jacobian matrix of (13)-(14) is

$$
\mathrm{J}=\left[\begin{array}{cc}
z^{\star} & \partial \dot{z} / \partial x \\
0 & -\gamma
\end{array}\right]
$$

Since $\gamma>0$ the determinant is negative.

\section{Proof of proposition 2}

To prove that proposition we write the balanced growth rate as

$$
\gamma=(1 / \sigma) \alpha(1-\tau)(\tau-(p s / y))^{(1-\alpha) / \alpha}-\rho
$$

where we used $p s / y=\beta x-\phi$. This shows that $\gamma$ is maximized for $\phi=x=0$. 


\section{Proof of proposition 3}

Setting $\beta=0$, the debt to GDP ratio evolves according to

$$
\dot{x}=x\left(\frac{\dot{b}}{b}-\frac{\dot{y}}{y}\right)=\phi+x\left(\frac{\rho-r(1-\sigma)}{\sigma}\right),
$$

where we used $\dot{y} / y=\dot{k} / k=(-\rho+r) / \sigma$ for $\beta=0$. Taking into account that $r$ is constant on a BGP, the solution to the differential equation is given by,

$$
x(t)=\frac{-\phi \sigma}{\rho-r(1-\sigma)}+e^{t(\rho-r(1-\sigma)) / \sigma}\left(x(0)+\frac{\phi \sigma}{\rho-r(1-\sigma)}\right) .
$$

Noting that $\dot{y} / y=\gamma=(-\rho+r) / \sigma$ holds on a BGP, we get for the level of public debt

$$
b(t)=y_{0} e^{\gamma t}\left(C_{1}+C_{2} e^{(r-\gamma) t}\right),
$$

with $C_{1}=-\phi \sigma /(\rho-r(1-\sigma))$ and $C_{2}=x(0)+\phi \sigma /(\rho-r(1-\sigma))$.

Thus, for $r>\gamma \leftrightarrow \rho-r(1-\sigma)>0$ the limit of the present value of public debt is given by,

$$
\lim _{t \rightarrow \infty} e^{-r t} b(t)=y_{0} C_{2} .
$$

For $r<\gamma \leftrightarrow \rho-r(1-\sigma)<0$, the limit of the present value of public debt is obtained as,

$$
\lim _{t \rightarrow \infty} e^{-r t} b(t)=+\infty(-\infty), \quad \text { for } \quad \phi>0 \quad(\phi<0)
$$

\section{Proof of proposition 4}

To prove that proposition, we solve $\dot{z} / z=0$ with respect to $z$ and insert the resulting expression into $\dot{x} /(x \psi(\cdot))$ giving,

$$
q_{1}:=(1-\tau) \alpha c_{p}(x, \cdot)^{(1-\alpha) / \alpha}(1-1 / \sigma)-\beta+\phi / x+\rho / \sigma .
$$

A solution of $q_{1}(\cdot)=0$ with respect to $x$ gives a BGP. The function $q_{1}(\cdot)$ has the following property,

$$
\lim _{x \rightarrow 0} q_{1}(\cdot)=+(-) \infty, \text { for } \phi>(<) 0,
$$


with $\bar{x}:=(\tau+\phi) / \beta$. The derivative of $q_{1}(\cdot)$ is,

$$
\frac{\partial q_{1}(\cdot)}{\partial x}=(-\beta)(1-\tau)(1-\alpha) c_{p}(x, \cdot)^{(1 / \alpha)-2}(1-1 / \sigma)-\phi / x^{2}<(>) 0
$$

for $1 / \sigma<1, \phi>0(1 / \sigma>1, \phi<0)$. Consequently, if there exists a BGP it is unique. For $1 / \sigma>1, \phi>0$ and for $1 / \sigma<1, \phi<0$ the derivative $\partial q_{1}(\cdot) / \partial x$ changes signs so that multiple BGPs can arise.

\section{Proof of corollary 1}

To prove the corollary we define

$$
q_{2}(\cdot):=x q_{1}(\cdot)=x(1-\tau) \alpha c_{p}(x, \cdot)^{(1-\alpha) / \alpha}(1-1 / \sigma)-x \beta+\phi+x \rho / \sigma
$$

with

$$
\lim _{x \rightarrow 0} q_{2}(\cdot)=\phi, \lim _{x \rightarrow \bar{x}} q_{2}(\cdot)=\phi+\bar{x}((\rho / \sigma)-\beta) .
$$

The condition in the corollary implies $\phi+\bar{x}((\rho / \sigma)-\beta)<0(>0)$ for $1 / \sigma<1, \phi<0$ $(1 / \sigma>1, \phi>0)$. Thus, $q_{2}(\cdot)$ starts at $\phi<(>) 0$ and converges to $\phi+\bar{x}((\rho / \sigma)-\beta)<0$ $(>0)$ for $1 / \sigma<1, \phi<0(1 / \sigma>1, \phi>0)$. Consequently, existence of a BGP implies that there are multiple BGPs. To see that there are exactly two BGPs we study the second derivative of $q_{2}(\cdot)$ that is given by,

$$
\begin{aligned}
\frac{\partial^{2} q_{2}(\cdot)}{\partial x^{2}}= & -2(1-\tau)(1-\alpha) c_{p}(x, \cdot)^{-1+(1-\alpha) / \alpha} \beta(1-1 / \sigma)+ \\
& \beta^{2} x(1-\alpha) c_{p}(x, \cdot)^{-2+(1-\alpha) / \alpha}(1-\tau)(1-1 / \sigma)(-1+(1-\alpha) / \alpha)
\end{aligned}
$$

With $1 / \sigma<1$ the function $q_{2}(\cdot)$ is strictly concave for $\alpha \geq 1 / 2$. For $\alpha<1 / 2$ there exists a unique point of inflection given by $\tilde{x}=2 \alpha \bar{x}$ so that there exist at most two values of $x$ that solve $q_{2}(\cdot)=0$. For $1 / \sigma>1$ the function $q_{2}(\cdot)$ is strictly convex for $\alpha \geq 1 / 2$. For $\alpha<1 / 2$ there again exists a unique point of inflection given by $\tilde{x}=2 \alpha \bar{x}$. This proves the corollary. 


\section{Proof of proposition 5}

The Jacobian matrix of (13)-(14) with permanent deficits is

$$
\mathrm{J}=\left[\begin{array}{cc}
z^{\star} & \partial \dot{z} / \partial x \\
x^{\star} \psi\left(x^{\star}, \cdot\right) & \partial \dot{x} / \partial x
\end{array}\right]
$$

with

$$
\begin{aligned}
& \frac{\partial \dot{z}}{\partial x}=z^{\star}\left(\beta(1-\alpha) c_{p}(\cdot)^{-1+(1-\alpha) / \alpha} \alpha^{-1}(1-(1-\tau) \alpha / \sigma)-\beta c_{p}(\cdot)^{-1+1 / \alpha} / \alpha\right) \\
& \frac{\partial \dot{x}}{\partial x}=x^{\star} \psi(\cdot)\left(\beta(1-\alpha) c_{p}(\cdot)^{-1+(1-\alpha) / \alpha} \alpha^{-1}(1-(1-\tau) \alpha)-\beta c_{p}(\cdot)^{-1+1 / \alpha} / \alpha-\phi / x^{2}\right)
\end{aligned}
$$

The determinant is computed as

$$
\operatorname{det} \mathrm{J}=z^{\star} x^{\star} \psi(\cdot)\left(-\beta(1-\alpha)(1-\tau) c_{p}^{-1+(1-\alpha) / \alpha}(1-1 / \sigma)-\phi / x^{2}\right)=z^{\star} x^{\star} \psi(\cdot)\left(\partial q_{1} / \partial x\right),
$$

with $\psi=\alpha(\tau+\phi-\beta x) /(\alpha(\tau+\phi)-\beta x)$ and $q_{1}$ defined in the proof of proposition 4 . Thus we have,

$$
\begin{aligned}
& \operatorname{det} \mathrm{J}<0 \leftrightarrow \partial q_{1} / \partial x<0 \text { for } x^{\star}<\alpha(\tau+\phi) / \beta, \\
& \operatorname{det} \mathrm{J}<0 \leftrightarrow \partial q_{1} / \partial x>0 \text { for } x^{\star}>\alpha(\tau+\phi) / \beta .
\end{aligned}
$$

For $1 / \sigma<1$ and $\phi>0$ the function $q_{1}$ crosses the horizontal axis from above such that $\operatorname{det} \mathrm{J}<0$ for $x^{\star}<\alpha(\tau+\phi) / \beta$ and for $1 / \sigma>1, \phi<0$ the function $q_{1}$ crosses the horizontal axis from below so that $\operatorname{det} \mathrm{J}<0$ for $x^{\star}>\alpha(\tau+\phi) / \beta$.

For $1 / \sigma>1, \phi>0$ the function $q_{1}$ first crosses the horizontal axis from above and then from below. Consequently, the first BGP is saddle point stable if and only if $x_{1}^{\star}<\alpha(\tau+\phi) / \beta$ and the second BGP is saddle point stable if and only if $x_{2}^{\star}>\alpha(\tau+\phi) / \beta$.

For $1 / \sigma<1, \phi<0$ the function $q_{1}$ first crosses the horizontal axis from below and then from above. Consequently, the first BGP is saddle point stable if and only if $x_{1}^{\star}>\alpha(\tau+\phi) / \beta$ and the second BGP is saddle point stable if and only if $x_{2}^{\star}<\alpha(\tau+\phi) / \beta$. Thus, there is only one or no saddle point stable BGP in this case. 


\section{Proof of proposition 6}

To prove that proposition we note that the balanced growth rate rises (declines) for $\partial(p s / y) / \partial \phi<(>) 0$. Since $p s / y=\beta x-\phi$ we get

$$
\frac{\partial(p s / y)}{\partial \phi}=-1+\beta \frac{\partial x}{\partial \phi}
$$

The expression $\partial x / \partial \phi$ is obtained by implicit differentiation as

$$
\frac{\partial x}{\partial \phi}=-\frac{\partial q_{1} / \partial \phi}{\partial q_{1} / \partial x}
$$

with $q_{1}$ from the proof of proposition 4 which gives

$$
\frac{\partial(p s / y)}{\partial \phi}=\frac{C_{1}+\phi / x^{2}-\beta / x-C_{1}}{\partial q_{1} / \partial x}=\frac{\beta x-\phi}{\left(-x^{2}\right)\left(\partial q_{1} / \partial x\right)}
$$

with $C_{1}=\beta(1-\tau)(1-\alpha)(\tau+\phi-\beta x)^{(1 / \alpha)-2}(1-1 / \sigma)$. Since $\beta x-\phi=p s / y>0$ the balanced growth rate rises (declines) for $\partial q_{1} / \partial x>(<) 0$ which holds for $x^{\star}>(<) \alpha \bar{x}$ for a saddle point stable BGP (see the proof of proposition 5). Inserting $\alpha \bar{x}$ in equation (10) gives the result.

\section{References}

Arrow, K.J. and M. Kurz (1970) Public Investment, the Rate of Investment and Optimal Fiscal Policy. Baltimore: The Johns Hopkins Press.

Ballasone, F., M. Francese and A. Pace (2011) "Public Debt and Economic Growth in Italy", Quaderni di Storia Economica / Economic History Working Papers, no. 11, October 2011, Banca d'Italia, Rome.

Barro, R.J. (1979) "On the determination of public debt", Journal of Political Economy, Vol. 87, No. 5, pp. 940-971.

Barro, R.J. (1990) "Government spending in a simple model of endogenous growth", Journal of Political Economy, Vol. 98, No. 5, pt. 2, pp. S103-S125. 
Bohn, H. (1998) "The behaviour of U.S. public debt and deficits", Quarterly Journal of Economics Vol. 113, No. 3, pp. 949-963.

Checherita-Westphal, C. and P. Rother (2010) "The impact of high and growing debt on economic growth. An empirical investigation for the euro area", ECB working paper series number 1237, Frankfurt.

Checherita-Westphal, C., A.H. Hallett and P. Rother (2012) "Fiscal sustainability using growth-maximising debt targets", ECB working paper series number 1472, Frankfurt.

Egert, B. (2012) "Public Debt, Economic Growth and Nonlinear Effects: Myth or Reality?" OECD Economics Department, Working Papers 993, OECD Publishing, Paris.

Ferreira, C. (2009) "Public Debt and Economic Growth: a Granger Causality Panel Data Approach", School of Economics and Management, Technical University of Lisbon, working paper 24/2009, Lisbon.

Fincke, B. and A. Greiner (2011) "Do large industrialized economies pursue sustainable debt policies? A comparative study for Japan, Germany and the United States", Japan and the World Economy, Vol. 23, No. 3, pp. 202-213.

Fincke, B. and A. Greiner (2011a) "Debt sustainability in selected euro area countries. Empirical evidence estimating time-varying parameters", Studies in Nonlinear Dynamics \& Econometrics, Vol. 15, No. 3, article 2.

Futagami, K., T. Iwaisako and R. Ohdoi (2008), "Debt policy rule, productive government spending, and multiple growth paths", Macroeconomic Dynamics, Vol. 12, No. 4, pp. $445-462$.

Ghosh, A.R., J.I. Kim, E.G. Mendoza, J.D. Ostry and M.S. Qureshi (2013) "Fiscal fatigue, fiscal space and debt sustainability in advanced economies", The Economic Journal, Vol. 123, Issue 566, pp. F4-F30. 
Greiner, A. (2008) "Does it pay to have a balanced government budget?" Journal of Institutional and Theoretical Economics (JITE), Vol. 164, No. 3, pp. 460-476.

Greiner, A. (2013) "Debt and growth: Is there a non-monotonic relation?" Economics Bulletin, Vol. 33, No. 1, 340-347.

Greiner, A., U. Köller and W. Semmler (2007) "Debt sustainability in the European Monetary Union: Theory and empirical evidence for selected countries", Oxford Economic Papers, Vol. 59, No. 2, pp. 194-218.

Havranek, T., R. Horvath, Z. Irsova and M. Rusnak (2013) "Cross-country heterogeneity in intertemporal substitution", IES Working Paper: 11/2013, Institute of Economic Studies, Faculty of Social Sciences, Charles University, Prague.

Kamiguchi, A. and T. Tamai (2012) "Are fiscal sustainability and stable balanced growth simultaneously attainable?" Metroeconomica, Vol. 63, No. 3, pp. 443-457.

Kumar, M.S. and J. Woo (2010) "Public debt and growth", IMF working paper number WP/10/174, Washington: IMF.

Panizza, U. and A.F. Presbitero (2013) "Public debt and economic growth in advanced economies: A Survey", Swiss Journal of Economics and Statistics, Vol. 149, No. 2, pp. $175-204$. 